\title{
Addiction to the nicotine gum in never smokers Jean-François Etter*
}

\author{
Address: Institute of social and preventive medicine, University of Geneva, 1 rue Michel-Servet, CH-1211 Geneva 4, Switzerland \\ Email: Jean-François Etter* - jean-francois.etter@imsp.unige.ch \\ * Corresponding author
}

Published: 17 July 2007

BMC Public Health 2007, 7:159 doi:10.1 186/147/-2458-7-159

This article is available from: http://www.biomedcentral.com/147I-2458/7/I59

(C) 2007 Etter; licensee BioMed Central Ltd.

This is an Open Access article distributed under the terms of the Creative Commons Attribution License (http://creativecommons.org/licenses/by/2.0), which permits unrestricted use, distribution, and reproduction in any medium, provided the original work is properly cited.
Received: 13 November 2006 Accepted: 17 July 2007

\begin{abstract}
Background: Addiction to nicotine gum has never been described in never smokers or in never users of tobacco.

Methods: Internet questionnaire in 2004-2006 in a self-selected sample of 434 daily users of nicotine gum. To assess dependence on nicotine gum, we used modified versions of the Nicotine Dependence Syndrome Scale (NDSS), the Fagerström Test for Nicotine Dependence and the Cigarette Dependence Scale.

Results: Five never smokers used the nicotine gum daily. They had been using the nicotine gum for longer than the 429 ever smokers (median $=6$ years vs 0.8 years, $p=0.004$ ), and they had higher NDSS-gum Tolerance scores (median $=0.73$ vs $=-1.0, p=0.03$ ), a difference of 1.5 standard deviation units. Two never smokers had never used smokeless tobacco, both answered "extremely true" to: "I use nicotine gums because I am addicted to them", both "fully agreed" with: "after a few hours without chewing a nicotine gum, I feel an irresistible urge to chew one" and: "I am a prisoner of nicotine gum".

Conclusion: This is to our knowledge the first report of addiction to nicotine gum in never users of tobacco. However, this phenomenon is rare, and although the long-term effect of nicotine gum is unknown, this product is significantly less harmful than tobacco.
\end{abstract}

\section{Background}

Nicotine replacement therapy (NRT) is effective to treat tobacco dependence, and about one third of smokers ever used NRT products [1-3]. In many countries, NRT products can be obtained on general sales, in drugstores or on the internet, without a medical prescription and without counselling [3]. NRT products are therefore easily accessible to nonusers of tobacco. Since nicotine has the potential to be addictive, there is a possibility that non-users of tobacco may become addicted to NRT products. There is to our knowledge, however, no published case of addiction to NRT products in never smokers or in never users of tobacco. Among former smokers who used the nicotine gum to quit smoking, the prevalence of dependence on the gum is very low, about one percent [4-6]. The proportion of never-smokers and never-users of tobacco among regular nicotine gum users is unknown and, contrary to what many people believe, this proportion may not necessarily be zero. The aim of this study was to assess whether we could identify never-smokers and never-users of tobacco who used the nicotine gum or were addicted to it.

\section{Methods}

We posted a questionnaire on nicotine gum use on the internet between September 2004 and March 2006, in 
English, on the smoking cessation website http://stoptabac.ch $[7,8]$. The questionnaire was listed second on Google.co.uk when typing "nicotine gums" (tested November 8, 2006).

A link to the questionnaire was posted on other smoking cessation websites. The questionnaire is available at [9]. This study was not submitted to an ethics committee, but participants were informed that their answers were stored on file and had the option to refuse storage of their data.

Questions included: Have you ever used nicotine replacement products (i.e. nicotine gums, patches, tablets or inhalers)? (Yes, no); Do you currently use nicotine replacement products? (Every day, occasionally, used in the past, never used); Currently, on how many days per week do you use nicotine chewing gums?; How long did your current episode of nicotine gum use last?; Currently, how many nicotine chewing gums do you use per day? Questions also covered intention to stop using the gum, serious attempts to stop using nicotine gum in the past year, duration of the last attempt to stop using the gum and urges to use nicotine gum during the last quit attempt. We defined never smokers as people who answered "No" to: "Have you ever smoked 100 cigarettes or more in your lifetime?" and: "No, I never was a smoker" to: "Do you currently smoke tobacco?". Use of smokeless tobacco was assessed by email, in never smokers who reported using nicotine gum daily in the online questionnaire.

Because we know of no published, validated questionnaire measuring dependence on the nicotine gum, we modified the Fagerström Test for Nicotine Dependence (FTND), the Nicotine Dependence Syndrome Scale (NDSS) and the Cigarette Dependence Scale (CDS) to assess gum dependence [10-13]. FTND and CDS are unidimensional, whereas NDSS covers 5 dimensions of dependence: Drive, Priority, Tolerance, Continuity and Stereotypy [11]. In all items, we replaced the words "cigarette" by "nicotine gum", and "smoking" by "using" or "chewing nicotine gum". We computed NDSS standardized scores as recommended [11]. We dropped the NDSS item: " Even if travelling a long distance, I'd rather not travel by airplane because Iwouldn't be allowed to smoke", because it cannot easily be modified for nicotine gum use. We modified the NDSS item "I tend to avoid restaurants that don't allow smoking, even if I would otherwise enjoy the food" to: "I tend to avoid places where I cannot chew nicotine gum, even if I would otherwise enjoy the company". We used Mann-Whitney U-tests to compare medians and chi-square tests to compare proportions.

\section{Results}

There were 848 participants in the online survey, including 436 daily users of nicotine gum, 68 occasional (nondaily) users and 344 non-users. Among the 434 daily gum users who indicated their smoking status, there were 349 former smokers (80\%), 80 current smokers (18\%) and 5 never smokers $(1.2 \%)$. The median age of these 5 never smokers was 44 years (range 38 to 59 years), they comprised 3 women and one man (one missing answer), and 3 people who lived in the USA and one in the UK (one missing answer).

Compared with the 429 ever smokers who used the gums daily, the 5 never smokers tended to have higher nicotine gum dependence scores for all FTND-gum, CDS-gum and NDSS-gum scales, but statistically significant differences were observed only for the NDSSgum Tolerance score (never smokers: median $=0.73$, ever smokers: median $=$ 1.0, Mann-Whitney U-test: $\mathrm{p}=0.03$ ), which represents a difference of 1.5 standard deviation units. Three of the 4 never smokers who answered this NDSS question, but only $14 \%$ of ever smokers answered "extremely true" to: "compared to when I first started using nicotine gum, I can use many, many more nicotine gum now before I start to feel nauseated or ill" (chi-square $=13.2, \mathrm{p}=0.01$ ). In addition, the duration of the current episode of nicotine gum use was longer in the 5 never smokers than in the 429 ever smokers (median $=6$ years vs 0.8 years, Mann-Whitney U-test: $\mathrm{p}=0.004$ ).

We obtained more information by e-mail from 4 of the 5 never smokers who used the nicotine gum daily. Three of these 4 people confirmed that they had never smoked, but one woman said she had smoked a few cigarettes occasionally. Three said they had never used smokeless tobacco, but one man said he had used small amounts of tobacco snuff as a child, decades before he started using the nicotine gum. They authorized us to report their comments.

E., female, 38, USA, was using the nicotine gum for 2 years, used 5 gums/day

"I've never smoked. My sister had some nicotine gum when she was trying to quit smoking, and I happened to try a piece. It seemed to wake me up and give me an energy boost, which I liked. I don't drink coffee, so I use the gum to wake me up when I'm feeling drowsy."

S., female, 39, USA, was using the nicotine gum for 10 years, used 15 gums/day

"I have never smoked cigarettes. I started using nicotine gum by chance, when a medical student offered them to me to try. I still use them because I am addicted to nico- 
tine, and can not seem to quit using them even if have tried."

In e-mail messages, these two participants (E. and S.) answered that they had never used smokeless tobacco, had never abused or been dependent on other substances and had never been diagnosed with a psychiatric illness. In the online questionnaire, these 2 never-users of tobacco reported addiction levels to the gum of 95 and 98 on a scale of $0-100$, FTND-gum ratings of 2 and 5, CDSgum ratings of 44 and 56 and NDSS-gum ratings of -0.9 and 0.42 .

Both answered "extremely true" to: "I use nicotine gums because I am addicted to them" and: "I use nicotine gum because I a cannot stop using them" and: "I use nicotine gum to deal with stress". Both reported that stopping using all NRT products would be "very difficult". Both "fully agreed" with: "after a few hours without chewing a nicotine gum, I feel an irresistible urge to chew one", "I am a prisoner of nicotine gum" and: "after chewing a nicotine gum, I am able to concentrate better". Both "seriously considered" stopping NRT in the next 6 months. One had made a serious attempt to stop using the gums during the previous year, during which she felt a "very strong" urge to use nicotine gum. This failed quit attempt lasted 30 days.

In the online survey, three additional participants reported being never smokers. Two of them could be further contacted by e-mail:

G., female, 59, USA, was using the nicotine gum for 10 years, used 10 gums/day

"During the time [my husband] was a smoker, I was a "social smoker". I would smoke at parties [his cigarettes] and occasionally at home after dinner or with a drink. I never bought or carried cigarettes with me, I only smoked his or on occasion my co-worker's. [...] About 15 years ago, my husband [...] started chewing prescription Nicorette, and I chewed it occasionally as well. When it became available over the counter, we both just continued to chew it, and I became more and more addicted to it. I started with one or two pieces occasionally, then one or two a day, and finally up to a dozen pieces a day, and continued at the rate for several years, maybe $4-5$ years [...]. It is really awful to be addicted to a substance, and I reached a point where my throat hurt, my teeth hurt, I had a headache most days, [...] but I still kept chewing. And it is so expensive - I was spending over a \$100 a month on it."

In an e-mail message, this participant (G.) said she had never used smokeless tobacco and had never abused or been addicted to other substances. She had been diag- nosed with depression after a severe traumatic stress and took antidepressants (paroxetine) for several years after that. She said: "I think the depression was a natural reaction to [the traumatic stress]. Nicotine was part of my selfmedication duringall this".

A., male, 49, UK, was using the nicotine gum for 6 years, used 20 gums/day

This participant reported that he had occasionally used small quantities of tobacco snuff as a child, between the age of 11 and 14, but not any more since then. He also said he had suffered from depression and had been prescribed fluoxetine by his family doctor. He reported:

"I have never smoked any tobacco product or even marijuana in my life. I have experimented with LSD, psilocybin, amphetamines but not currently using any of these. Several years ago, purely out of interest I bought a pack of nicotine gum to see what the effect of nicotine would be. I remember feeling quite ill [...]. It was about a year or so later [...], I remembered my pack of nicotine gums and started to use them maybe two or three times a day. I didn't expect that I would ever become addicted [...]. Within a short period of time I was using 15 pieces per day. Just as people say about smoking, I genuinely enjoyed using the gum [...]. On several occasions I stopped using it 'cold turkey'. The symptoms were mainly light headedness and difficulty in concentration, most of the time I just bought more gums - like a smoker [...]. Most of my life I have suffered from depression [...]. I hadn't considered until then that nicotine could have such a stabilising effect. I would very much like to quit. The gum is very expensive [...]. Nicotine gum is a form of self-medication [...]. I would argue that my state of mind has become more calm and regulated since using nicotine gums and reverts to previous, unsatisfactory state when I stop using nicotine gums. [...] I started using the illicit drugs above shortly before using nicotine gums on a regular basis."

These two participants (G. and A.) reported levels of addiction to the gums of 80 and 95 on a $0-100$ scale, FTND-gum ratings of 5 and 6, CDS-gum ratings of 50 and 55 and NDSS-gum ratings of -0.21 and 0.67 . Both answered "extremely true" to: "I use nicotine gums because I am addicted to them". Both had made a serious attempt to stop using NRT in the previous year, but only one reported more details about that quit attempt, which lasted 60 days and was accompanied with "very strong" urges to use nicotine gum. Both reported usually chewing their first gum of the day 10 minutes after waking up, both "fully agreed" with: "after a few hours without chewing a nicotine gum, I feel an irresistible urge to chew one", "the idea of not having any nicotine gum causes me stress", 
"sometimes I drop everything to go out and buy nicotine gums", "chewing a nicotine gum calms me down when I am stressed", and: "after chewing a nicotine gum, I am able to concentrate better".

\section{Discussion}

In an online study of nicotine gum users, we identified 5 never smokers who used the nicotine gum daily. There was reasonable evidence that most of these 5 never smokers were addicted to the nicotine gum. Of particular interest are the two cases of never users of tobacco (including smokeless tobacco) who reported being addicted to the nicotine gum. This is to our knowledge the first report of such cases.

Surprisingly, these 5 never smokers had been using the nicotine gum for many more years than ever smokers, and they tended to be more dependent on the gum. For cigarette dependence, FTND scores of 5 or more reflect a strong dependence $[14,15]$. Four of the 5 never smokers had FTND-gum scores of 5 or more, which suggests that these people were strongly dependent on the gum. In a previous study, the average CDS score in daily smokers was 47 , and daily smokers who had CDS scores $>=50$ smoked on average 25 cigarettes per day and smoked their first cigarette within 10 minutes of waking up [13]. Three of the 5 never smokers in the present study had CDS-gum scores at or above 50, which suggest that they were strongly dependent on the nicotine gum. Never smokers had substantially higher NDSSgum Tolerance scores than ever smokers, which may reflect that ever smokers were already tolerant to nicotine before they started using the gum.

Never-smokers reported classical criteria of dependence, such as a compulsion to use the gum, use in higher dosage and for a longer duration than initially intended, withdrawal symptoms, unsuccessful attempts to stop and gum use despite its high cost [16,17]. Their open-ended answers also reflected classical criteria of dependence, such as failed quit attempts followed by urges to use the gum, relief of withdrawal symptoms (e.g. difficulty concentrating) by gum use, and withdrawal symptoms (e.g. urges to use the gum after a few hours).

People who were addicted to the nicotine gum could easily find our questionnaire, because it was listed on top of the list in Google. In spite of this effective enrolment strategy, we identified only two never-users of tobacco among daily gum users, which suggests that NRT use in neverusers of tobacco is a rare phenomenon. Similarly, a previous survey in people who responded to a newspaper ad that read: "Are you addicted to nicotine gum?" could not enrol any never smoker [5]. Furthermore, there was no report of subsequent nicotine dependence in never smok- ers who were treated with nicotine for ulcerative colitis, aphtous ulcers and sleep-disordered breathing [18-21]. The short-tem effect of the nasal spray was also tested in never smokers, with no report of never smokers getting addicted to this fast delivery product [22-24]. In a previous survey, $0.3 \%$ of adolescent never smokers reported past daily use of NRT, but none was reported as being addicted to NRT [25]. However, some adolescents will endorse using any product when a list is presented to them, e.g. $0.4 \%$ said they used a fictitious nicotine "Nic-T" product [26]. In two surveys in the USA, $2.7 \%$ and $4.6 \%$ of school drug counsellors indicated that nicotine patches and gums were abused by adolescents, but these "NRT abusers" were mainly smokers who used NRT while smoking, and only $7 \%$ to $16 \%$ of these "NRT abusers" were never smokers [27]. The latter study did not report any case of NRT dependence in adolescent never smokers [27]. Similarly, studies in representative samples of the UK and Swedish general populations found no never-user of tobacco among users of NRT [28]. A review of postmarketing surveillance data in the USA found no report of primary dependence to the nicotine gum and patch,[29] and only 39 cases of dependence on the nicotine gum were reported per million prescriptions to smokers, in surveillance data [30]. Therefore, addiction to nicotine gum in never smokers is probably very rare. Furthermore, there may be few adverse consequences of being addicted to the nicotine gum, except for the financial cost and the inconvenience of permanent chewing. In particular, NRT products are safe even in patients with heart disease, [31,32] and there was no untoward effect of 5 years of nicotine gum use in the Lung Health Study [33]. Thus, long-term use of NRT is not known to be harmful.

Participants volunteered to take part in our study after finding a link to the questionnaire on Google. This enabled anyone who was looking for information on the nicotine gum to find the questionnaire easily. As a result, our sample consisted of a self-selected group of people who proactively searched the web for information on the nicotine gum, perhaps because they worried about their nicotine gum use. This sample is therefore not representative of all nicotine gum users. In particular, only $2 \%$ of USA households who purchased nicotine gums purchased them monthly for 6 months or more, [34] and only $6 \%$ of participants in a nicotine gum trial used the gum for 24 weeks or more [35] These figures contrast sharply with the median duration of 8 months of NRT use in ever smokers in our survey, which suggests that our method oversampled long-term users of NRT. It is therefore not possible to extrapolate from our data a population prevalence of never smokers among daily gum users. Our aim was however not to determine this prevalence, but to test whether we could identify any never-user of tobacco or any nonsmoker among nicotine gum users. Our findings have 
important implications for the understanding of the effects of nicotine, since it was believed until now that nicotine addiction could be maintained, but not initiated by the nicotine gum [5].

\section{Conclusion}

Addiction to the nicotine gum in never smokers is probably quite rare, but this study suggests that it can occur.

\section{Competing interests}

The Institute of Social and Preventive Medicine of the University of Geneva received financial support from Pfizer and Novartis to develop, under the supervision of the author, online smoking cessation programs for users of nicotine replacement products. The author acted as a consultant for Pfizer.

\section{Funding}

No external funding.

\section{Acknowledgements}

Vincent Baujard, from the Health On The Net Foundation (HON), Geneva, Switzerland, developed the software for data collection.

\section{References}

I. Stead L, Lancaster T: Nicotine replacement therapy for smoking cessation: Cochrane systematic review. Int J Epidemiol 2005 , 34: I00I-2.

2. Al-Delaimy WK, Gilpin EA, Pierce JP: When California smokers use nicotine replacement therapy, most are trying to quit smoking. Tob Control 2005, 14:359-60.

3. Shiffman S, Gitchell J, Pinney JM, Burton SL, Kemper KE, Lara EA: Public health benefit of over-the-counter nicotine medications. Tob Control 1997, 6:306-10.

4. Hughes JR: Dependence potential and abuse liability of nicotine replacement therapies. Biomed Pharmacother 1989, 43: II-7.

5. Hughes JR, Pillitteri JL, Callas PW, Callahan R, Kenny M: Misuse of and dependence on over-the-counter nicotine gum in a volunteer sample. Nicotine Tob Res 2004, 6:79-84.

6. Hughes JR: Dependence on and abuse of nicotine replacement medications: an update. In Nicotine safety and toxicity Edited by: Benowitz NL. Oxford: Oxford University Press; 1998.

7. Bock B, Graham A, Sciamanna C, Krishnamoorthy J, Whiteley J, Carmona-Barros R, Niaura R, Abrams D: Smoking cessation treatment on the Internet: content, quality, and usability. Nicotine Tob Res 2004, 6:207-19.

8. Etter JF, Perneger TV: Effectiveness of a computer-tailored smoking cessation program: a randomized trial. Arch Intern Med 200I, 161:2596-601.

9. Survey for users of nicotine chewing gums [http://www.stoptabac.ch/en/Gums/]

10. Heatherton TF, Kozlowski LT, Frecker RC, Fagerstrom KO: The Fagerstrom Test for Nicotine Dependence: a revision of the Fagerstrom Tolerance Questionnaire. Br J Addict |991, 86: III $9-27$.

11. Shiffman S, Waters A, Hickcox M: The nicotine dependence syndrome scale: a multidimensional measure of nicotine dependence. Nicotine Tob Res 2004, 6:327-48.

12. Etter JF, Le Houezec J, Perneger TV: A self-administered questionnaire to measure dependence on cigarettes: the cigarette dependence scale. Neuropsychopharmacology 2003, 28:359-70.

13. Etter JF: A comparison of the content-, construct- and predictive validity of the cigarette dependence scale and the Fagerstrom test for nicotine dependence. Drug Alcohol Depend 2005, 77:259-68.
14. Moolchan ET, Radzius A, Epstein DH, Uhl G, Gorelick DA, Cadet JL, Henningfield JE: The Fagerstrom Test for Nicotine Dependence and the Diagnostic Interview Schedule: do they diagnose the same smokers? Addict Behav 2002, 27: I0I-I3.

15. Kozlowski LT, Porter CQ, Orleans CT, Pope MA, Heatherton T: Predicting smoking cessation with self-reported measures of nicotine dependence: FTQ, FTND, and HSI. Drug Alcohol Depend 1994, 34:211-6.

16. American Psychiatric Association: Diagnostic and Statistical Manual of Mental Disorders - Fourth Edition, (DSM-IV) Washington D.C., American Psychiatric Association; 1994.

17. World Health Organization: The ICD-I0: classification of mental and behavioural disorders: clinical descriptions and diagnostic guidelines Geneva, World Health Organization; 1992

18. Davila DG, Hurt RD, Offord KP, Harris CD, Shepard JW Jr: Acute effects of transdermal nicotine on sleep architecture, snoring, and sleep-disordered breathing in nonsmokers. $\mathrm{Am}$ Respir Crit Care Med 1994, I 50:469-74.

19. Sandborn WJ, Tremaine WJ, Leighton JA, Lawson GM, Zins BJ, Compton RF, Mays DC, Lipsky J], Batts KP, Offord KP, Hurt RD, Green J: Nicotine tartrate liquid enemas for mildly to moderately active left-sided ulcerative colitis unresponsive to firstline therapy: a pilot study. Aliment Pharmacol Ther 1997, I I:663-7I.

20. Sandborn WJ, Tremaine WJ, Offord KP, Lawson GM, Petersen BT, Batts KP, Croghan IT, Dale LC, Schroeder DR, Hurt RD: Transdermal nicotine for mildly to moderately active ulcerative colitis. A randomized, double-blind, placebo-controlled trial. Ann Intern Med 1997, 126:364-7I.

21. Bittoun R: Recurrent aphthous ulcers and nicotine. Med J Aust I99|, I 54:47|-2.

22. Kalman D, Smith SS: Does nicotine do what we think it does? A meta-analytic review of the subjective effects of nicotine in nasal spray and intravenous studies with smokers and nonsmokers. Nicotine Tob Res 2005, 7:317-33.

23. Perkins KA, Gerlach D, Broge M, Grobe JE, Wilson A: Greater sensitivity to subjective effects of nicotine in nonsmokers high in sensation seeking. Exp Clin Psychopharmacol 2000, 8:462-7I.

24. Perkins KA, Gerlach D, Broge M, Grobe JE, Sanders M, Fonte C, Vender J, Cherry C, Wilson A: Dissociation of nicotine tolerance from tobacco dependence in humans. J Pharmacol Exp Ther 200I, 296:849-56.

25. Klesges LM, Johnson KC, Somes G, Zbikowski S, Robinson L: Use of nicotine replacement therapy in adolescent smokers and nonsmokers. Arch Pediatr Adolesc Med 2003, I 57:517-22.

26. Adams EH, Korberly B, Maquire MK, Franzon MA: Post marketing surveillance of nicotine replacement products. Poster presented at the conference of the Society for Research on Nicotine and Tobacco, Paris, France, 19-22 September 200I

27. Hyland A, Bradford D, Gitchell J: Drug counselor report of adolescents abuse of nicotine replacement therapy. J Addict Dis 2005, 24:105-13.

28. Ramström LM: Use of of nicotine replacement therapy with and without prescription. Future directions in nicotine replacement therapy (proceedings). Paris, October 1993. Chester: ADIS International; 1994.

29. Spyker DA, Alderfer RJ, Goetsch RA, Longmire AW, Kramer ED: Post-marketing reports of adverse events and prolonged use of nicotine polacrilex resin and the nicotine patch. Rockville: Food and Drug Administration, unpublished manuscript. 29 March 1996

30. Spyker DA, Alderfer RJ, Goetsch RA, Armstrong GD, Longmire AW, Kramer ED: Post-marketing adverse events associated with the nicotine patch and polacrilex resin in the United States. [Abstract]. Clin Pharmacol Ther 1996, 59:159.

31. Joseph AM, Norman SM, Ferry LH, et al.: The safety of transdermal nicotine as an aid to smoking cessation in patients with cardiac disease. N Engl J Med 1996, 335: 1792-8.

32. Mahmarian JJ, Moye LA, Nasser GA, et al.: A strategy of smoking cessation combined with nicotine patch therapy reduces the extent of exercise-induced myocardial ischaemia. J Am Coll Cardiol 1997, 30: 125-30.

33. Murray RP, Bailey WC, Daniels K, Bjornson WM, Kurnow K, Connett JE, Nides MA, Kiley JP: Safety of nicotine polacrilex gum used by 3,094 participants in the Lung Health Study. Lung Health Study Research Group. Chest 1996, 109:438-45. 
34. Shiffman S, Hughes JR, Pillitteri JL, Burton SL: Persistent use of nicotine replacement therapy: an analysis of actual purchase patterns in a population based sample. Tob Control 2003, 1 2:310-6.

35. Shiffman S, Hughes JR, Di Marino ME, Sweeney CT: Patterns of over-the-counter nicotine gum use: persistent use and concurrent smoking. Addiction 2003, 98: 1747-53.

\section{Pre-publication history}

The pre-publication history for this paper can be accessed here:

http://www.biomedcentral.com/1471-2458/7/159/pre pub

Publish with Bio Med Central and every scientist can read your work free of charge

"BioMed Central will be the most significant development for disseminating the results of biomedical research in our lifetime. " Sir Paul Nurse, Cancer Research UK

Your research papers will be:

- available free of charge to the entire biomedical community

- peer reviewed and published immediately upon acceptance

- cited in PubMed and archived on PubMed Central

- yours - you keep the copyright

Submit your manuscript here:

http://www.biomedcentral.com/info/publishing_adv.asp 